\title{
Listening to and Crafting Stories: Cultivating activism in online doctoral students
}

\author{
Carey Borkoski \\ Johns Hopkins University \\ cborkoski@jhu.edu \\ Brianne Roos \\ Loyola University Maryland \\ bhiggins@loyola.edu
}

\begin{abstract}
The Johns Hopkins University (JHU) online EdD program prepares students as scholar-practitioners who become leaders and agents of change across educational contexts. Advocating for equity and social justice requires our students to not only immerse themselves in the relevant literature and learn the traditional skills of applied research but to master the art of communication through a sort of storytelling. Storytelling, in this sense, represents a means to gather and analyze data and understand and integrate diverse perspectives to engage and persuade relevant stakeholders (Moezzi et al., 2017). Johns Hopkins' first-year EdD programming and coursework emphasize the use of deficit-free language to understand people and problems, value the consideration of diverse perspectives, and structure students' inquiry with a systems-approaches to explore contextual problems using a mixed methods research paradigm. Together, the program's approach to student learning and practice-oriented courses and dissertation research contribute to training scholar-practitioners as activists who ask relevant questions, draw on multiple perspectives to craft potential solutions, adapt to a variety of contexts and circumstances, engage with diverse stakeholders, reflect on their own assumptions, and admit to and learn from mistakes throughout the process. Through a detailed accounting and examination of the JHU onboarding features and processes, particular course content and assignments, as well as the interplay of these elements, this paper will demonstrate how attending to language, perspective taking, context, and research inquiry support the development of scholar-practitioners as activists.
\end{abstract}

\section{KEYWORDS}

communication through storytelling, deficit-free language, systems-approach, activist inquiry

The Johns Hopkins University (JHU) online EdD program prepares students as scholar-practitioners who become leaders and agents of change across educational contexts including $\mathrm{k}-12$, higher education, and other education-related sectors. Advocating for equity and social justice requires our students to not only immerse themselves in the relevant literature and learn the traditional dispositions, skills, and knowledge of trained researchers, but also to master the art of communication through a powerful tool, named storytelling. Traditional research training might include an understanding of research methods paradigms, approaches to collecting and analyzing different sources of data, and effectively disseminating those findings. Storytelling, as suggested, combines traditional research approaches with intentional understanding and the integration of diverse perspectives to engage and persuade relevant stakeholders (Moezzi et al., 2017). In this paper, we will explore how doctoral student program onboarding and first-year coursework contribute to the development of EdD students as activists.
While students in this EdD program are known as scholarpractitioners, it would also be accurate to suggest that these students are trained similarly to what Warren et al. (2016) refer to as community-engaged scholars. In this capacity, students work with families, teachers, districts, schools, and students to identify and address important education problems. Training these scholars requires a unique and different set of skills, knowledge, and dispositions than the traditional Ph.D. student. For example, Warren et al. (2016) explain that this countercultural approach requires students to cultivate a community that values the students' whole selves, build horizontal relationships, attend to their own identity, tell evidence-informed stories, and develop identities that include community-engaged scholarship. JHU EdD students graduate with a mix of traditional and nontraditional approaches to research methodology, ready to craft and share convincing stories of complex problems in education that lead to action through intentional intervention. More specifically, our students become education activists capable of integrating their knowledge of research methods with storytelling skills to investigate, understand, and disseminate
New articles in this journal are licensed under a Creative Commons Attribution 4.0 United States License. Program and is cosponsored by the University of Pittsburgh Press.

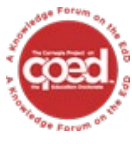

This journal is supported by the Carnegie Project on the Education Doctorate: A Knowledge Forum on the EdD (CPED) cpedinitiative.org 
complex Problems of Practice (PoP) through an examination of the literature and analysis of relevant evidence, including quantitative data and the lived experiences of people in their education contexts.

\section{ONBOARDING}

Doctoral students are not necessarily protest-organizing and rally-attending activists, but Jacoby (2017) suggests that these scholar-practitioners activists take many forms and engage in a variety of activities, such as critical reflection and compromise, which contribute to both identifying, interrogating, and addressing problems found in their institution. Our EdD students bring with them a wealth of practitioner knowledge, and they learn how integrate their contextual understanding with their new knowledge and training to identify and address real and complex problems in education, and look towards implementing change by engaging with stakeholders, rather than at stakeholders.

The first-year EdD curriculum emphasizes the knowledge and application of traditional research methods paradigms with a focus on mixed methods, structured inquiry through a systems-approach, the use of deficit-free language, many ways of knowing (Hartman, 1990), and the consideration of diverse perspectives to explore contextual problems. The program includes traditional coursework, dissertation research, and a recently added formal, first-year onboarding process. Together, these approaches and strategies transition incoming students into scholar-practitioners prepared to address the myriad of educational challenges, beginning with their own PoP.

Onboarding is described in corporate literature as part of the process of integrating employees into the culture of an organization (i.e., organizational socialization) to facilitate their success in a new position (Bauer et al., 2007). Holmes et al. (2016) suggest a similar process of onboarding online doctoral students, with explicit attention to the culture of the program, including procedures, practices, and beliefs. This onboarding process at JHU begins upon students' acceptance to the program and extends through the first year of the three-year program. Onboarding includes synchronous and asynchronous engagement, with attention to community-building, perspective-taking, and deficit-free language that prepares students for deep engagement with coursework, dissertation research, and education activism. Each cohort of doctoral students is assigned a faculty member as their cohort lead, and a Teaching Assistant (TA) who came from an earlier cohort. One of the first onboarding goals that both the cohort lead and TA establish is a culture of inclusion and respect among the cohort members in the hopes of promoting engagement with the students' own team and community participants.

Mertens (2007) suggests that inclusion and continuous assessment of identity and power are critical for transformative research. During the onboarding process, students share their perspectives on various aspects of online learning in preparation for online doctoral studies. For example, the faculty lead for the cohort asks students about anticipated areas of comfort and challenges in the program, and responds to questions including time management, efficacy using technology, course content, and the embedded dissertation model. Students then begin to consider the perspectives of various stakeholders based on their PoP during onboarding meetings. The cohort lead asks questions such as: "what do you think your students' parents would say about the problem?" and "how do you think your superintendent might view the problem?" to encourage an alternative point of view. These alternative viewpoints set the stage for student activism as they will need to engage with a variety of stakeholders (Stufflebeam, 2003) when dissertation work transitions from problem-focused to intervention-focused during the second year of the program.

Throughout the first year of the program, students learn to describe their proposed PoPs using deficit-free language. Additionally, students are asked to bring their whole selves to this process as a means to interact and participate in authentic ways. The program does not ask students to assimilate or fit into a particular culture determined by faculty members' research interests. Rather, students bring their own relevant and contextual problems to the program and they actively work to contribute to and shape their own learning experiences and communities around the problem.

Part of this process includes attending to, naming, and celebrating the skills and knowledge that students already have when they enter the program using deficit-free language. As an example, some doctoral students dwell on what they do not bring to the program (e.g., research experience, statistical expertise); that is, students focus on what they lack. The cohort lead and TA work, very early, to change this story to focus on students' current assets and contributions as scholar-practitioners with unique perspectives. Being new to research does not negate the expertise that students bring to the program, and students are called on to participate using their contextual expertise regularly in onboarding activities and coursework. Shifting students' mindsets from what they lack to what they bring may, in turn, help to shift their perspectives on participants, research contexts, and their articulated PoP.

\section{SHIFTING PERSPECTIVES}

Just as many students arrive to the program describing themselves as lacking research knowledge and skills, students also tend to describe their PoP related to a factor that is lacking. For example, a student may describe their own students as having a lack of motivation or their fellow teachers as lacking skills to effectively integrate technology in their classrooms. During the onboarding process, students identify and expand their perspective on their position by participating a strengths-based appreciative inquiry approach and related activities (Cooperrider \& Whitney, 2000) to acknowledge and build on their expertise as scholar-

practitioners. Similarly, the faculty lead for the cohort facilitates small group workshops in which students describe their PoP using deficit free language by considering what is happening in their contexts, as opposed to what is not happening. Workshops involve challenging students to discuss their PoP by considering the following questions:

1. What is the problem?

2. What is bothering you in your context that lead you to this problem?

3. Why does it matter?

4. How would you describe the problem based on what you see?

Warren et al. (2016) suggest students' lived experiences of an education problem provide necessary depth to a research project and also reveal a student researcher's identity related to the problem. The workshops begin to shed light on students' perspectives as single perspectives on the problem and include questions about the specific contexts in which students work, with 
inquiry about what makes the situation a problem from multiple stakeholders' perspectives. As students participate in workshops to develop their PoP, they also engage in perspective-taking on their own EdD learning experiences.

In the context of this discussion of training education activists with a combination of traditional and nontraditional approaches, the EdD coursework focuses on the traditional training found in first-year courses for doctoral students. Our course instructors rely on a systems approach to examining problems of practice, engage with diverse literature to understand and define their research problems, and train students in research methods and the application of these approaches to the students' own work. Through course readings, synchronous and asynchronous discussions, and a variety of assignments, students learn the requisite knowledge and skills of a researcher. However, while the emphasis of the coursework is on the more traditional dispositions of researchers, such as literature synthesis, research methods, academic writing, and data analyses, students also continue to explore the value of working with and in a community, diverse perspectives and data sources, and revisit their identity as they investigate their PoP with their instructors, advisors, and peers. These paths of exploration may be considered contrary to the more formal PhD. For example, EdD faculty intentionally model the use of deficit-free language during synchronous sessions and in writing through discussion posts and feedback on students' written work. Additionally, students' course assignments and literature reviews are informed by multiple diverse perspectives on their PoP, including historical, sociological, anthropological, and economic standpoints.

Students learn about how each discipline applies to education and then apply the disciplinary perspectives to their own PoP. Consideration of multidisciplinary perspectives on education problems and their own PoP primes students to use a systems approach in their research because students are getting accustomed to looking at problems through perspectives beyond their own. A systems approach provides a structure for students and requires them to consider diverse perspectives about both their own EdD journeys and their research focus. Students are introduced to several systems frameworks such as ecological systems theory (Bronfenbrenner, 1994) and improvement science (Bryk et al., 2015) to learn about how systems thinking frames inquiry into problems. Students construct concept maps to display their systems and begin to cast a wide net to learn about a broad range of factors that contribute to their PoP. Oftentimes students enter the program with strong and well-informed, but somewhat narrow ideas about the factors contributing to their PoP. Applying systems theories and improvement science concepts to problems in papers, synchronous and asynchronous discussion, and through graphic depiction helps students to recognize the contribution of multiple and varied disciplines and the range of factors that contribute to problems in education. As concept maps expand, describing a problem using deficit-free language gradually becomes more natural as the contributing factors are illustrated and the problem emerges as not what is lacking, but rather what is occurring in a particular context.

\section{CULTIVATING STORYTELLERS}

Students enter the research methods course with multidisciplinary perspectives of their PoP and an understanding of the "complex networks of many interacting variables" relevant to their research (Cabrera \& Cabrera, 2015, p.12). The first assignment in the initial research methods course asks students to complete an observation of their own contexts. Students look at their schools, offices, or classrooms with the perspective of a researcher and they begin to demonstrate that their perceived problem of practice is indeed a problem and that it exists in context. Faculty feedback on students' observations guides students to recognize biases and encourages them to question assumptions that may or may not align with the reality of their contexts. The observation assignment and subsequent research methods work with quantitative, qualitative, and mixed-methods of inquiry to systematically guide students from thinking as practitioners to thinking as practitioner-scholars whose work is to empirically examine a problem with an open mind, rather than with confirmation bias. Students' perspectives are broadened as they learn and apply methods of scholarly inquiry, continuing the process of transitioning from practitioners to practitioner-scholars. Research methods coursework emphasizes the mixed methods paradigm as a pragmatic research approach that capitalizes on the relative strengths of quantitative and qualitative inquiry by coupling measurable survey data with contextual accounts of participants' lived experiences (Johnson \& Onwuegbuzie, 2004), thus continuing to prioritize multiple perspectives.

The EdD curriculum integrates traditional research methods training with opportunities to learn how to effectively synthesize literature, articulate research findings, and use meaningful storytelling to convey their research to diverse audiences. Clark and Rossiter (2008) suggest storytelling is a way to "make sense of chaos" so that elements of the problem come together through linkages to stakeholders' actual experiences (p. 62). Students are uniquely positioned to learn about perspectives, opinions, and facts different from their own views on the problem. Their own perspectives may be challenged but listening and empathizing with diverse stakeholders is valuable (Hendriks et al., 2019) because shared experiences and connections across diverse stakeholders allow people to think creatively about solutions to problems and to envision a different future. Like EdD students who arrive at the program with a problem articulated from their own perspectives, Vygotsky (1978) asserts that people first draw on their own experiences, then expand on those experiences to include others' experiences using imagination (Arroyo, 2017). The EdD program cultivates student creativity and imagination through community building, scholarly dialogue, the development of data literacy skills, research methods and design, critical reading of relevant literature, and scholarly discourse. Together, these become the storytelling tools of emerging education activists.

The combination of program features contributes to cultivating doctoral students who finish their first year having fully considered their identified PoP and potential mechanisms by which to address this contextual problem. Early onboarding that includes a vibrant student learning community allows for exploration and discourse of difficult topics and perspectives. With these first onboarding experiences, students enter their first doctoral courses with a changed mindset ready to examine their PoP with a new set of questions and perspectives. Finally, while much of the coursework focuses on the traditional approaches to research, the coursework and the instructors also make space for conversations and work that reinforces the important features introduced and examined during the onboarding. For example, students learn about reflexivity and member checking (Guba, 1981) to continually check in with themselves to make sure they consider their own biases and the voices of participants. 
Moreover, the program encourages students to consider a mixed methods approach to their dissertation research and Mertens (2018) described mixed methods as a transformative approach to address complex problems that involve multiple stakeholders. She also proposed a value branch of inquiry in which researchers use mixed methods, with a focus on qualitative inquiry, to discover the realities that various stakeholders construct around a problem. Using a mixed method paradigm asks students to develop a comprehensive perspective and plan for their problem of practice by adopting and practicing research inquiries that reflect respect, inclusivity, and the multiple realities of their stakeholders.

\section{CONCLUSION}

The symbiosis between first-year coursework and the onboarding programming contributes to furthering student development as scholar-practitioners. Throughout the first year, EdD students learn how to tell the compelling stories of an education PoP by understanding diverse views, integrating stakeholder voices, and crafting solutions to support social justice and equity. Students ask relevant questions, draw on multiple perspectives to craft potential solutions, adapt to a variety of contexts and circumstances, engage with diverse stakeholders, reflect on their own assumptions, and admit to and learn from mistakes throughout the process. Intentional onboarding programming and first-year coursework focused on diverse perspectives, systems approaches, deficit-free language, and mixed methods inquiry set the stage for first-year online doctoral students to transition from practitioner-expert novice-scholars to wellinformed scholar-practitioners who aspire to educational activism.

\section{REFERENCES}

Arroyo, K. K. (2017). Creative policymaking: Taking the lessons of creative placemaking to scale. Artivate: A Journal of Entrepreneurship in the Arts, 6, 58-72.

Bauer, T. N., Bodner, T., Erdogan, B., Truxillo, D. M., \& Tucker, J. S. (2007). Newcomer adjustment during organizational socialization: A metaanalytic review of antecedents, outcomes, and methods. Journal of Applied Psychology, 92(3), 707-721. https://doi.org/10.1037/00219010.92.3.707

Bronfenbrenner, U. (1994). Ecology models of human development. In T. N. Postlewaite \& Husen, T. (Eds.), International encyclopedia of education (2nd ed., Vol. 3, pp. 1643-1647). Elsevier.

Bryk, A. S., Gomez, L. M., Grunow, A., \& LeMahieu, P. G. (2015). Learning to improve: How America's schools can get better at getting better. Harvard Educational Press.

Cabrera, D., \& Cabrera, L. (2015). Systems thinking made simple: New hope for solving wicked problems. Odyssean Press.

Clark, M. C., \& Rossiter, M. (2008). Narrative learning in adulthood. New Directions for Adult and Continuing Education, 119, 61-70. https://doi.org/10.1002/ace.306
Cooperrider, D. L., \& Whitney, D. (2000). A Positive Revolution in Change: Appreciative Inquiry. In D. L. Cooperrider, P. F. Sorensen, Jr., D. Whitney, and T. F. Yaeger (Eds.), Appreciative inquiry: Rethinking human organization toward a positive theory of change (pp. 3-27) Stipes Publishing

Guba, E. G. (1981). Criteria for assessing the trustworthiness of naturalistic inquiries. Educational Technology Research and Development, 29, 7591. https://doi.org/10.1007/BF02766777

Hartman, A. (1990). Many ways of knowing. Social Work, 35, 3-4. https://doi.org/10.1093/sw/35.1.3

Hendriks, C. M., Ercan, S. A., \& Duus, S. (2019). Listening in polarised controversies: A study of listening practices in the public sphere. Policy Sciences, 52, 137-151.

Holmes, B., Willis, K., \& Woods, E. (2016). Strategic onboarding of online doctoral students: Creating a pathway to academic persistence. Asian Journal of Social Sciences and Management Studies, 3(2), 136-139.

Jacoby, B. (2017). The new student activism: Support students as agents of social change. Journal of College and Character, 18, 1-8. https://doi.org/10.1080/2194587X.2016.1260479

Johnson, R. B., \& Onwuegbuzie, A. J. (2004). Mixed methods research: A research paradigm whose time has come. Educational Researcher, 33, 14-26. https://doi.org/10.3102/0013189X033007014

Mertens, D. (2007). Transformative Paradigm: Mixed Methods and Social Justice. Journal of Mixed Methods Research. 1. 212-225. https://doi.org/10.1177/1558689807302811.

Mertens, D. M. (2018). Mixed methods design in evaluation. Thousand Oaks: Sage.

Moezzi, M., Janda, K. B., \& Rotmann, S. (2017). Using stories, narratives, and storytelling in energy and climate change research. Energy Research \& Social Science, 31, 1-10. https://doi.org/10.1016/j.erss.2017.06.034

Stufflebeam, D. L. (2003). The CIPP model for evaluation. In D. L. Stufflebeam \& T. Kellaghan (Eds.), The international handbook of evaluation (pp. 3161). Kluwer Academic Publishers.

Vygotsky, L. S. (1978). Mind in society: The development of higher psychological processes. Harvard University Press.

Warren, M. R., Park, S. O., \& Tieken, M. C. (2016). The formation of community-engaged scholars: A collaborative approach to doctoral training in education research. Harvard Educational Review, 86, 233 260. https://doi.org/10.17763/0017-8055.86.2.233 